\title{
Línguas, mediações e aprendizagens à luz do Quadro Europeu Comum de Competência Digital
}

ANTÓNIO MOREIRA

Universidade de Aveiro

\begin{abstract}
There being a Common European Framework of Reference for Languages that regulates learning, teaching and evaluation of this domain, we will discuss its dual association to the CEFR for Digital Competence, which we understand as dialogic since Digital Technologies are part of the teaching of any language, let alone other domains. Our approach will be provocative in that, taking into account what has been called soft skills, it will show parallels that each of the teachers contribute to learning, teaching and evaluation, with implications for teacher training and teachers' respective responsibilities in the impacts of their activity in the future of their students.
\end{abstract}

Keywords - CEFR, Digital Competence, Languages, Mediation, Learning

\section{Introdução}

O QECRL fornece uma base comum para a elaboração de programas de idiomas, diretrizes curriculares, exames, livros didáticos, etc. para toda a Europa, descrevendo, de forma abrangente, o que os alunos de línguas necessitam para usarem uma linguagem que lhes permita comunicar, bem como os conhecimentos e capacidades que têm que devem desenvolver para poderem atuar comunicacionalmente com eficácia. Esta definição abrange também o contexto cultural no qual determinada língua se encontra estabelecida, sendo que o quadro define níveis de proficiência - no caso das línguas, 6 - que permitem mensurar o progresso dos alunos ao longo, não só da sua aprendizagem dita formal, como também ao longo da sua vida. São assim objetivos principais do QECR, de acordo com [1]: promover o plurilinguismo e a diversificação na escolha das línguas no currículo; apoiar o desenvolvimento e a demonstração do perfil plurilingue de alunos individuais; desenvolver e rever o conteúdo dos currículos de línguas e definir descritores positivos exequíveis adaptados à idade, aos interesses e às necessidades dos alunos; conceção e desenvolvimento de livros didáticos e material didático; apoiar a formação de professores e a cooperação entre professores de diferentes idiomas; melhorar a qualidade e o sucesso na aprendizagem, ensino e avaliação, facilitando a transparência nos testes e a comparabilidade das certificações.

Pois bem, no caso do Quadro Europeu Comum de Referência para a Competência Digital, doravante QECRCD, que define competência digital enquanto utilização segura, crítica e criativa das tecnologias digitais para atingir metas relacionadas com o trabalho, o emprego, a aprendizagem, o lazer, a inclusão e a participação na sociedade [2]; kit de sobrevivência: social, económico, político e cultural [3,4]; e motor para a modernização dos mercados de 
trabalho, o reforço do capital humano, a empregabilidade e a competitividade, os seus objetivos não são muito díspares dos apontados para o QECRL, e que sucintamente elencamos como facilitar o desenvolvimento/compreensão da competência digital na Europa; criar um sistema de certificação comparável entre países; e informar o planeamento estratégico conducente à formulação de políticas de educação, formação e emprego; e avaliação individual e/ou profissional. Neste momento cabe uma referência a [5] que, no seu projeto de Pós-doutoramento, por mim supervisionado, se encontra a desenvolver trabalho de relevo nesta área.

\section{Que ligações}

O QECR tem for finalidade fornecer uma base compartilhada para a reflexão e comunicação entre diferentes parceiros, incluindo aqueles que se encontram diretamente envolvidos na formação de professores e na elaboração de programas de línguas, diretrizes curriculares, livros didáticos, exames, etc., em todos os estados membros do Conselho da Europa. É oferecido aos utilizadores enquanto ferramenta descritiva que permite refletir sobre decisões e práticas, situando e coordenando esforços em benefício dos alunos de línguas em cada contexto ou situação particular. É, portanto, um artefacto flexível que se adapta a cada contexto específico de aplicação, aspeto fulcral e totalmente refletido no sistema de níveis que pode ser adaptado e explorado de forma flexível para o desenvolvimento de objetivos de ensino-aprendizagem, desenvolvimento de sequências e materiais didáticos, formulação de curricula e avaliação de desempenhos.

Elaborado com dois objetivos principais em mente, o CEFR pretende incentivar os praticantes de todos os tipos no domínio da linguagem, incluindo os próprios alunos de línguas, a refletir sobre questões como as sugeridas nas «Notas para o utilizador» [6, p. xii], no que diz respeito à análise de situações de ensino-aprendizagem, e tornar mais fácil para os profissionais se entenderem entre si e com quem interagem o que desejam que os alunos sejam capazes de fazer e como podem fazê-lo.

De qualquer modo, devemos ter bem presente que não é o QECR que define o que se deve dizer aos professores e aos alunos ou como executar esta ou aquela tarefa. O QECR chama meramente a atenção para aspetos a ter em conta; não fornece receitas pré-preparadas para aplicação em qualquer caso, contexto ou circunstância. Não lhe cabe definir objetivos para os utilizadores seguirem ou métodos e estratégias a desenvolver e/ou implementar. Essa é a tarefa do docente, do autor de manuais, do político que ocupa a tutela da educação, e até 
mesmo do autodidata. Seria, contudo, injusto da minha parte afirmar que o Conselho da Europa não reflita sobre estes aspetos. Com efeito, vários especialistas contribuíram para projetos de políticas linguísticas e pensaram e trabalharam nos princípios e na prática de aprendizagem, ensino e avaliação de línguas ao longo dos anos, atividade que ainda mantêm.

\section{Um pouco de história da ligação PEL/LEM com as TIC}

Teve lugar um estudo que envolveu os Estados membros do Conselho da Europa sobre o uso do QECR na formação de professores, a reforma dos curricula de línguas estrangeiras e o desenvolvimento de materiais didáticos, tendo a questão das responsabilidades sobre o uso adequado do QECR sido discutida durante um fórum intergovernamental em 2007. A relação entre o QECR e o Portefólio Europeu de Línguas (PEL) foram também desenvolvidos em paralelo. O PEL é um instrumento baseado no QECR com o qual os alunos, individualmente, podem refletir sobre a aprendizagem e registrar seu progresso. Usando o QECR em contextos específicos, este Quadro não oferece soluções pré-fabricadas, mas deve ser sempre adaptado às exigências dos contextos específicos, como por exemplo o ensino e aprendizagem de uma língua em particular, ou de idiomas associados ao Quadro. Existe, assim, uma necessidade particular de uma interpretação e adaptação cuidadosa quando o esquema descritivo do Quadro e os níveis de proficiência são, por exemplo, utilizados para explorar as necessidades comunicativas de migrantes adultos e para orientar a avaliação da sua proficiência na língua da comunidade de acolhimento. O Quadro não é específico para o idioma, mas é essencial para a definição de objetivos de ensino-aprendizagem de idiomas específicos.

Já a integração das TIC no currículo das línguas estrangeiras modernas (LEM) e sua implementação na sala de aula representam uma série de desafios importantes que se referem à forma como as ferramentas e tarefas digitais afetam a aquisição da linguagem, bem como o desenvolvimento cognitivo, emocional, social e moral geral dos estudantes. Infelizmente ainda não se sabe o suficiente sobre o impacto do ensino-aprendizagem digitalmente assistido na aquisição de línguas e confesso que desconheço o real impacto das abordagens baseadas na investigação sobre a integração das TIC nas LEM, apesar da profusão de estudos que reclamam esse estatuto, alguns dos quais realizados ou orientados por mim próprio. Os professores aplicam intuições e experiências acumuladas através do ensino assistido, não digital, às tecnologias emergentes, muitas vezes numa espécie de «compromisso de fé», parecido com a frase «ora vamos ver o que é que isto que faço sem tecnologias dá se eu lhe juntar as ditas». 
É assim importante um maior grau de sistematicidade, profundidade e reflexão sobre a integração das TIC no ensino e aprendizagem de LEM, que tenha em conta fatores cognitivos, éticos, pragmáticos e, obviamente, pedagógicos. Também pertenço àquele grupo de pessoas que, embora acredite que as tecnologias emergentes podem, de facto, melhorar as aprendizagens, estas não o irão conseguir concretizar, a menos que efetiva e eficazmente refletidas e aproveitadas, o que exige compreender como as línguas se adquirem, que implicações cada ferramenta digital tem nessa aquisição, e como é que as TIC se encaixam no ecossistema individual do professor de línguas enquanto profissional e, especialmente, enquanto indivíduo. É que, parecendo existir um paradoxo entre o QECR para as Línguas e o QECR para a Competência Digital, este pode descrever-se do seguinte modo:

1. Enquanto o QERCL, nos seus seis níveis de proficiência para uma dada língua, me pode colocar numa posição de Avançado, equiparando-me a um falante, leitor, ouvinte e escritor muito próximo do nativo dessa língua, não espera de mim que seja um especialista em Linguística ou Gramática, um escritor reconhecido (por exemplo como Józef Teodor Nałęcz Korzeniowski, um polaco que se tornou famoso com o livro Heart of Darkness, já sob o nome britânico de Joseph Conrad), um bilingue tão perfeito que passe por nativo da língua, por exemplo ao ponto de me possibilitar passar por espião de Sua Majestade, do arquétipo convencionado pela indústria cinematográfica, e do qual fui testemunha na Universidade Estatal Lomonosov de Moscovo, na qual as docentes de Inglês todas vestiam como a Julie Andrews no filme Música no Coração, e todas elas tinham a mesma pronúncia e perfeição de fala da personagem Mary Poppins. E isto em 1995. Com efeito, este seria o nível C2 (Mestria), que afirma: «The capacity to deal with material which is academic or cognitively demanding, and to use language to good effect at a level of performance which may in certain respects be more advanced than that of an average native speaker.» Wow!

2. O QCERCD, conhecido também por DigComp, congrega oito níveis de proficiência, para 21 competências em 5 áreas de competência. Estas áreas são Literacia de informação e de dados; Comunicação e colaboração; Criação de conteúdo digital; Segurança; e Resolução de problemas. Como se pode ver, à partida até não assusta, e é de prever que também estes oito níveis desçam para seis. De qualquer modo, e acoplando 1 e 2, temos um caminho a percorrer que não é somente responsabilidade do docente de TIC. Também nós, docentes de Língua temos não só que atingir níveis de competência digital que nos capacitem para a sua integração no ensino (e nas nossas 
vidas), de modos que até agora não havíamos refletido de forma aturada. No limite, e adaptando o nível C2 (Mestria) acima, poderíamos redigi-lo do seguinte modo: «The capacity to deal with material which is academic or cognitively demanding, and to use technologies to good effect at a level of performance which may in certain respects be more advanced than that of an average ICT engineer.» Double Wow!

Mas não se preocupem. Se atentarem na última versão do DigComp [7], onde o nível C2 (Mestria) poderia equivaler ao nível 8 (Altamente especializado), para cada uma das competências teriam que ser capazes de criar soluções para resolver muitos fatores que interagem entre si, relacionados com:

1. Literacia de informação e de dados: browsing, searching and filtering data, information and digital content, and propose new ideas and processes to the field.

2. Comunicação e colaboração: interacting through digital technologies and digital communication means, and propose new ideas and processes to the field.

3. Criação de conteúdo digital: content creation and edition in different formats, and self-expression through digital means, and propose new ideas and processes to the field.

4. Segurança: protecting devices and digital content, managing risks and threats, applying safety and security measures, and reliability and privacy in digital environments, and propose new ideas and processes to the field.

5. Resolução de problemas: technical problems when operating devices and using digital environments, and propose new ideas and processes to the field.

\section{Os desafios de Conti}

Parafraseando Conti [8], há doze desafios a ter em conta quando se tenta integrar tecnologias no ensino de LEM, e que o autor considera serem os mais importantes com base na sua própria experiência. O primeiro releva do poder de melhoria atribuível à integração das TIC para benefício das aprendizagens. Quando pensamos em utilizar uma aplicação de base digital, seja ela de que tipo for, nas aulas, devemos inquirir-nos sobre se tal utilização irá realmente melhorar o ensino e a aprendizagem em comparação com as abordagens que, não se socorrendo das TIC, consigo desenvolver, e como é que posso ter tal certeza. Os professores sentem-se muitas vezes compelidos a utilizar uma aplicação ou ferramenta web com receio de não parecer suficientemente inovador aos olhos dos seus pares ou alunos. No entanto, se a presença em sala de aula, o carisma, o humor, as técnicas de drama, etc., são 
mais atraentes do que o Kahoot, o iMovies, o Fluent-U, etc., seria um absurdo utilizar ferramentas de ensino mais «inovadoras» apenas para mostrar que estamos na crista da integração das TIC em sala de aula. Com efeito, e especialmente me contexto escolares ricos em tecnologias, os professores sentem que não usarem as TIC tanto quanto possível, estão de alguma forma a falhar à escola, aos alunos e a ser deixados para trás. Tal pode provocar, em alguns professores, especialmente nos menos experientes em TIC, sérios problemas de ansiedade e de empobrecimento da sua própria autoestima. Se esta questão não for devidamente abordada de início, a aprendizagem será afetada de forma bastante negativa, especialmente durante a primeira fase de integração, que é quando os professores estão a preparar o ano letivo. Neste caso, cabe à escola oferecer formação sobre como as ferramentas e tarefas digitais específicas realmente afetam a cognição dos alunos e a aquisição de linguagem em diferentes estágios de desenvolvimentos de proficiência em LEM. Os facilitadores de oficinas de tecnologias emergentes e os formadores de integração das TIC geralmente mostram aos professores como usar uma ferramenta específica ou realizar uma tarefa baseada em TIC, mas não aprofundam como a aquisição da língua melhora nos quatro skills convencionais ou porque é que tal integração digital é superior às estratégias não digitais. Experimentar uma ferramenta digital em prejuízo da aprendizagem dos alunos não só é eticamente errado por não garantir resultados, como reduz o já parco tempo de contato do professor com os alunos de línguas.

O segundo desafio releva das metáforas de aprendizagem de línguas em que vivemos, nomeadamente a que defendem a alfabetização digital dentro e fora do domínio da aprendizagem de línguas, como, por exemplo, as estratégias de e-Learning (ou seja, o conjunto de abordagens e técnicas que os alunos de LEM podem implementar para usar de forma independente recursos baseados na web para melhorar a sua aprendizagem). No entanto, se pretendemos criar hábitos de aprendizagem de línguas ao longo da vida nos nossos alunos, também temos o imperativo ético para impressionar a importância da interação entre seres humanos como capacidades fundamentais para a aprendizagem ao longo da vida. A integração das TIC nas LEM tem geralmente como resultado a proficiência oral e, em contrapartida, a negligência da fluência. E isto é geralmente devido a uma tendência de envolver os alunos em atividades lúdicas como os jogos online de baixo valor educativo, a criação de artefactos digitais através de aplicações únicas ou múltiplas de valor didático duvidoso, ou ainda a participação em projetos de aprendizagem assistida digitalmente, cujas 
atividades são enviesadas de modo a estarem de acordo com a previsão dos gostos dos alunos, tornando-se apelativas, mas vazias de conteúdo útil.

Ao esticar o processo de aquisição da linguagem em sala de aula com base num modelo pobre de aprendizagem, e principalmente baseado no digital, damos azo ao surgimento de metáforas de aprendizagem que não refletem verdadeiramente a forma como a linguagem é produzida e aprendida no mundo real. Tais metáforas - sejam ou não razoáveis - podem constituir o cerne das crenças dos nossos alunos quanto ao modo como as línguas são aprendidas para o resto de suas vidas. Cabe aos professores garantirem que há uma combinação equilibrada de tarefas digitais e não digitais e que as atividades orais destinadas a desenvolver a competência oral e a interação entre os alunos e entre estes e o professor habitem regularmente as aulas de LEM. É finalidade última do docente de línguas que os seus alunos possam comunicar e interagir com outros humanos, quer diretamente, quer por mediação tecnológica.

O desequilíbrio curricular é o terceiro desafio que, de acordo com o anteriormente referido, implica que a integração das TIC nas LEM tem o potencial de prejudicar o desenvolvimento da fluidez oral. Há, de qualquer modo, outros aspetos da aquisição da língua que também sofrem - a fluência e a transformação da gramática num mero elemento processual. No que diz respeito à audição, uma das razões é que não há muitas aplicações gratuitas e recursos baseados na web que promovam competências de compreensão oral. Outra questão diz respeito ao facto de que um aspeto muito importante da compreensão oral é frequentemente ignorado na sala de aula de cariz mais tecnológico. A compreensão oral refere-se à capacidade de ouvir, compreender e responder como parte de uma interação com um interlocutor. Quando os alunos trabalham com uma máquina, não há interlocutor para reagir, a menos que se utilizem aplicações como o Skype ou outras ferramentas digitais de comunicação síncrona. Quanto à gramática, existem conjugadores verbais online, aplicações e sites que envolvem trabalho em morfologia e sintaxe. Mas estes não são projetados para desenvolver qualquer controlo cognitivo sobre as estruturas da gramática-alvo, ou seja, desempenho escrito ou oral preciso em condições operacionais reais. As funções linguísticas e comunicativas, como, por exemplo concordar e discordar, informações de sequência, comparação e contraste também são frequentemente negligenciadas no PBL digital. É assim necessário verificar que em todas as unidades e planos de trabalho a integração baseada em TIC não resulta num excessivo foco na leitura, escrita, aprendizagem do vocabulário ao nível 
das palavras e nas práticas gramaticais do tipo de preenchimento mecânico, típicas das técnicas behavioristas.

A menos que os alunos sejam altamente proficientes na língua alvo, a manipulação digital tem o potencial de impedir desviem a sua atenção da aprendizagem de línguas. É este o quarto desafio, o da atenção dividida. Cortando, colando, conjugando aplicações, procurando efeitos de som, fazendo o download de imagens, etc., solicitam muitos recursos cognitivos dos alunos, que normalmente se queixam de se distraírem com as notificações que recebem do e-mail e da rede social enquanto se encontram de desenvolver uma tarefa. A consequência óbvia é uma atenção dividida que pode levar a uma retenção deficiente. Outra fonte de atenção dividida é a natureza dos média digitais. Numa interação típica com um professor ou um parceiro, um aluno de LEM pode contar com muitas pistas verbais e não-verbais (por exemplo, expressões faciais e gestos) que irão melhorar a compreensão ou esclarecer quaisquer dúvidas que ele ter. No entanto, quando se trata de ambientes digitais, aplicações ou ferramentas da Web que não se conformem ao princípio, por exemplo, da videoconferência, tipicamente síncrona, não são tão ricos em tópicos e podem representar vários desafios que podem desorientar os alunos menos conhecedores das TIC, ou que tenham menos à-vontade com elas. Com vinte ou mais alunos, não é raro ocorrerem duas ou três experiências deste tipo de problema em simultâneo numa mesma aula. Eis mais uma fonte de atenção dividida que carece que, por exemplo se opte por solicitar aos alunos que desativem as notificações das redes sociais e se estabeleçam sanções claras para aqueles que não anuírem a este conselho. Por outro lado, não se deverá permitir aos alunos que realizem manipulações digitais na aula, a menos que seja absolutamente necessário e justificado. Por fim, modelar o uso de uma aplicação ou ferramenta web até à exaustão, de modo que, enquanto docente, fique $100 \%$ convencido de que todos entendem como a utilizar. Para além disso, deve-se agrupar os alunos menos experientes em TIC, que são extremamente fáceis de identificar. Isso irá poupar o aborrecimento de andar de um lado para o outro na sala de aula, evitando que outros alunos se distraiam por pedidos de ajuda provenientes desses mesmos alunos.

O quinto desafio reduz-se à relação tempo-custo, e decorre do desafio anterior na medida em que, tendo em conta o exíguo tempo de contacto do professor para ensinar LEM, é imprescindível alocar a todos os minutos disponíveis uma boa dose de utilidade. As sugestões avançadas acima aplicam-se também aqui. 
A variedade constitui o sexto desafio. Tendo observado muitas aulas tecnológicas, nas quais os alunos passaram uma hora inteira a manusear o iPad sem aparente finalidade de aprendizagem, é votar os alunos ao abandono digital. Com efeito, existe evidência de investigação que afirma que muitos alunos acham este tipo de atividade tedioso e não propício à aprendizagem. Como em tudo na vida, na alimentação, no vestuário, na escola, e nas várias disciplinas do currículo, a variedade é essencial para combater a monotonia ou sensação de rotina. É de bom tom, e duvido que alguém discorde, que é essencial alternar o foco e tempo das tarefas, o trabalho individual e em grupo, as ferramentas/tarefas digitais e não digitais, as estratégias de ensino-aprendizagem, o enfoque em capacidades recetivas e produtivas, atividades lúdicas e acadêmicas, etc.

O sétimo desafio consiste em obter informação pela voz do próprio aluno. Vai sempre existir um momento em que teremos a necessidade de saber como é que a integração das TIC nas nossas aulas está a ser apreendida pelos alunos. Em vez de criar um questionário com escalas de Likert, ou de verdadeiro/falso, a ideia é questionar os alunos em entrevistas semiestruturadas individuais, envolvendo uma série de alunos de diferentes habilidades e género, ou mesmo despender algum tempo com a aplicação de técnicas de inquérito com grupos focais.

A avaliação da integração das TIC pelos pares de LEM constitui o oitavo desafio. Em muitas escolas, a integração das TIC em LEM é avaliada recorrendo ao modelo SAMR [9], muito vulgar no m-Learning. Tal pode prejudicar a aprendizagem de línguas estrangeiras por razões que podem ser visitadas em [10].

Já o nono desafio remete para as atitudes do aluno face às ferramentas digitais. Se a escola passar todo o tempo com iPads ou outro tipo de tablet, pode ter a certeza de que, na maioria das aulas, haverá um ou mais alunos que não retirarão qualquer proveito do uso do dispositivo para aprendizagem de línguas. E isto apresenta um dilema ético: se é imperativo diferenciar o nosso ensino de modo a atender às necessidades cognitivas e emocionais de cada aluno, o que é que se pode fazer para nos adequarmos às suas preferências de aprendizagem? Se, depois de várias tentativas, não se conseguir «vencer o aluno» e a sua aversão ao dispositivo móvel permanece, há três opções: 1. é difícil, mas eles necessitam de se adaptar; 2. Dê-se-lhes tarefas alternativas com resultados de aprendizagem semelhantes, mas recorrendo aos média tradicionais; 3. se usarmos o $i P a d$ para atividades rápidas de não mais de 10 a 15 minutos, alternadas com outras tarefas que não se socorrem de artefactos tecnológicos, verificaremos que esses alunos, afinal, até não se queixarão muito. 
A falta de consciência meta-digital de aprendizagem de línguas é o décimo desfio. A Internet oferece uma vasta gama de oportunidades de aprendizagem transformativa ${ }^{1}$. No entanto, os alunos precisam de ser dotados das ferramentas metacognitivas que lhes permitam aproveitar tais oportunidades. E isso implica ensinar os alunos a aprender com fontes de aprendizagem transformativa na Internet, ferramentas web e aplicações necessárias que possa usar de forma autónoma (por exemplo, como usar melhores programas de conjugação de verbos, o Youtube, o Memrise, fóruns de Wordreference, etc., para aprendizagem independente). Incorporar um ou mais programas explícitos de exercitação dos alunos em estratégias de aprendizagem meta-digital (por exemplo, estratégias de e-Learning) por ciclo de integração de TIC é uma possibilidade de enfrentar este desafio. Uma vez que os programas de exercitação de alunos exigem uma prática extensiva nas estratégias de ensino, devemos oferecer instruções apenas numa série limitada de estratégias por ciclo.

O desafio décimo-primeiro reporta-se aos problemas éticos. Com efeito, o fácil acesso ao meio digital e às aplicações implica o perigo de plágio, o copy-paste e o uso de tradutores online. Além de alertar os alunos para os perigos legais de tais práticas, os professores podem pedir-lhes que assinem um «termo contratual» no qual se comprometem a nunca praticar plágio nem utilizar tradutores online. Durante a fase inicial de integração, os professores terão de recordar aos alunos o contrato que assinaram, manter a sua consciência responsável e especificar as sanções que decorrem da violação das «regras» contratualizadas. A própria escola deveria ter este tipo de preceito no código de conduta e/ou regulamento que nela vigora, e verdade seja dita, já encontramos alguns (embora poucos) honrosos exemplos.

O décimo-segundo e último desafio remete para o binómio produto versus processo. Uma vez que muitas aplicações e workshops sobre tecnologias emergentes se preocupam com a produção de um artefacto digital (por exemplo, o iMovies), a integração das TIC em LEM é frequentemente caracterizada por uma preocupação excessiva com o produto da aprendizagem. No entanto, o ensino de línguas deve concentrar-se principalmente no desenvolvimento de competências de compreensão oral, oralidade, leitura e escrita (o processo de aprendizagem), em vez de apenas montar um filme digital, misturar aplicações ou proceder a apresentações, por exemplo em Powerpoint ou Prezzi (o produto). A produção de um artefacto digital pode ser favorável à aquisição da linguagem se tanto professores

\footnotetext{
${ }^{1}$ Para Mezirow (1996), a aprendizagem é concebida «como o processo de utilizar as interpretações anteriores, com vista a construir uma interpretação nova, ou uma interpretação alterada acerca do sentido da experiência pessoal em ordem a guiar a acção futura.» (Mezirow, 1996, p. 162).
} 
como alunos colocarem tanta ênfase no processo de aprendizagem como no seu produto final. Isto envolve a identificação dos níveis de complexidade e fluência em cada macro competência que são esperados dos aprendentes em cada etapa do desenvolvimento de um determinado projeto, fornecendo uma ampla prática, contextualizada, ao longo do processo com esses níveis de aspiração em mente.

\section{Conclusão}

A integração bem-sucedida das TIC no currículo de LEM e a sua implementação prática não são tarefas fáceis. Em primeiro lugar, exigem uma estrutura pedagógica consonante com qualquer abordagem educativa para a aprendizagem da L2 adotada pela equipe de LEM. Em segundo lugar, a sua eficácia será uma função da medida em que um professor sabe como, porquê e quando as ferramentas digitais melhoram a aprendizagem e afetam a cognição do aluno e a aquisição da língua. Em terceiro lugar, os professores precisam de controlar a tendência, comum durante o primeiro ciclo de integração, de deixarem o meio digital assumir e dirigir o ensino e a aprendizagem. Isto é muito comum entre os entusiastas das tecnologias emergentes e altamente prejudicial para a aprendizagem. Em quarto lugar, a consciencialização e estratégias de aprendizagem meta-digital dos alunos necessitam de ser aperfeiçoadas através de programas estruturados de aprendizagem destinadas a aprender. Em quinto lugar, os professores não devem esquecer que têm o imperativo ético de formar um falante equilibrado versado nas quatro macro competências e dotado de altos níveis de fluência e competência autónoma. A integração das TIC deve ser eclética e o docente deve estar consciente desse aspeto.

Em conclusão, a integração das TIC nas LEM ainda não é uma ciência exata. Para que seja bem-sucedida, a melhor receita é não nos deixarmos apressar pelo receio de sermos «deixados para trás» e não aparecermos como uma escola «inovadora» ou um professor «inovador». Os administradores e professores dos cursos devem sempre ter no seu consciente as necessidades linguísticas, cognitivas, sócio afetivas e morais dos seus alunos e integrar as TIC com essas necessidades em mente. Não se integre apenas para integrar. Em última análise, a integração das TIC deve ajudar, e não dirigir, a ensinar e aprender. O DigComp deve ser encarado como tal: com a naturalidade com que o QECR para as Línguas foi encarado, e que, presentemente, é um dado adquirido. 


\section{Referências bibliográficas}

[1] Council of Europe/Conseil de l'Europe (2001). Common European Framework of Reference for Languages: Learning, Teaching, Assessment. European Year of Languages 2001. Modern Languages Division Strasburg. Cambridge: Cambridge University Press. ISBN: HB 0521803136 - PB 0521005310.

[2] Ferrari, A. (2013). DIGCOMP: A Framework for Developing and Understanding Digital Competence in Europe. European Commission: JRC Scientific and Policy Reports. Luxembourg: Publications Office of the European Union.

[3] van Deursen, A. J. A. M. (2010). Internet Skills. Vital assets in an information society. University of Twente. Acedido em http://doc.utwente.nl/75133/ em 21 de maio de 2017.

[4] Eshet, Y. (2012). Thinking in the Digital Era: A Revised Model for Digital Literacy. Issues in Informing Science and Information Technology, 9, 267-276.

[5] Lucas, M. \& Moreira, A. (2017). Information and Communication Overload: Can DigComp Help? In Rui Pedro Figueiredo Marques, Joao Carlos Lopes Batista (Eds.), Information and Communication Overload in the Digital Age, Chapter: 7, Publisher: IGI Global, pp.157-175 (DOI: 10.4018/978-1-5225-2061-0.ch007).

[6] Council of Europe/Conseil de l'Europe (2001). Common European Framework of Reference for Languages: Learning, Teaching, Assessment. Language Policy Unit, Strasbourg. www.coe.int/lang-CEFR. Acedido em https://rm.coe.int/16802fc1bf\#page=4, 21 de maio de 2017.

[7] Carretero, S., Vuorikari, R., \& Punie, Y. (2017). DigComp 2.1: The Digital Competence Framework for Citizens with eight proficiency levels and examples of use. European Commission: JRC Scientific and Policy Reports. Luxembourg: Publications Office of the European Union.

[8] Conti, G. (2015). 12 challenges of ICT integration in MFL instruction. Acedido em https://gianfrancoconti.wordpress.com/2015/08/16/12-challenges-of-ict-integration-in-mfl-instruction, 18 de maio de 2017.

[9] Romrell, D., Kidder, Lisa C., \& Wood, E. (s.d). The SAMR Model as a Framework for Evaluating mLearning. Evaluating mLearning. 15 páginas. Acedido em https://www.google.pt/url? sa=t\&rct=j\&q= \&esrc $=$ s\&source $=$ web\&cd=10\&ved=0ahUKEwjchMzGwOvUAhXCWhQKHeJDC5kQFghUMAk\&url=http $\% 3$ $\mathrm{A} \% 2 \mathrm{~F} \% 2 \mathrm{Folc}$.onlinelearningconsortium.org\%2Fsites $\% 2 \mathrm{Fdefault} \% 2 \mathrm{Ffiles} \% 2 \mathrm{~F} 435-2313-1-$

LE.pdf\&usg=AFQjCNEZN8zvO DW7Dqs-0DFw1jr7cFz5UQ\&cad=rjt, 22 de maio de 2017.

[10] Conti, G. (2015). Of SAMR and SAMRitans - How the adoption of the SAMR model as a reference framework may be detrimental to foreign language learning. Acedido em https:/gianfrancoconti.wordpress.com/2015/05/27/ofsamr-and-samritans-how-the-adoption-of-the-samr-model-as-a-reference-framework-may-be-detrimental-to-foreignlanguage-learning/, 23 de maio de 2017. 